\title{
DGM 430 OFFSET WEB MACHINE PRINT QUALITY
}

\section{KUALITAS HASIL CETAK MESIN WEB OFFSET DGM 430}

\author{
Maulana Ibrahim ${ }^{a^{*}}$, Anton Hadiwibowo ${ }^{a}$, Mukhyidin Djaiz ${ }^{a}$, Henra Nanang Sukma ${ }^{\mathrm{a}}$ \\ a Teknik Grafika, Politeknik Negeri Media Kreatif, Indonesia \\ *Email: maulanaibrahim@gmail.com
}

\begin{abstract}
The review control activity, especially the decrease in the quality of the printed output, is one of the quality control parameters carried out by each company. To get quality, of course, the company does not remain silent, there are several things that need to be done or provided by the company to be able to support quality, namely man (human), machine (machine), material (material), and methods (methods). In the development of technology in an increasingly advanced digital world, companies want to continue to compete with a digital world by making breakthroughs, this of course makes the products produced by the company have a good or good quality level. In this study, there is an identification of the problem aspects that arise from the causes of the print results and how to get solutions to overcome the problems and factors that affect the quality of the print on the printed contents of the Cultural Arts Service Book using the DGM 430 Web Offset machine
\end{abstract}

\section{Keywords-Quality, Parameters, Web Offsets}

\begin{abstract}
Abstrak-Kegiatan pengendalian tinjauan khususnya penurunan kualitas hasil cetakan merupakan salah satu dari parameter pengendalian kualitas yang dilakukan oleh setiap perusahaan. Untuk mendapatkan kualitas tentunya perusahaan tidak berdiam saja, ada beberapa hal yang perlu dilakukan atau disediakan oleh perusahaan untuk dapat menunjang kualitas, yaitu man (manusia), machine (mesin), material (bahan), dan methode (metode). Dalam perkembangan teknologi di dunia digital yang semakin maju tentunya perusahaan ingin tetap bersaing dengan dunia yang serba digital dengan melakukan terobosan-terobosan tersebut, hal itu tentunya membuat produk yang dihasilkan oleh perusahaan mempunyai tingkat kualitas yang baik atau bagus. Dalam penelitian ini di dalamnya terdapat identifikasi aspek permasalahan yang timbul dari penyebab hasil cetak serta cara untuk mendapatkan solusi yang dilakukan untuk mengatasi masalah dan faktor yang mempengaruhi kualitas hasil cetak pada cetakan Isi Buku Dinas Seni Budaya menggunakan mesin Web Offset DGM 430.
\end{abstract}




\section{Kata Kunci- Kualitas, Parameter, Web Offset}

\section{PENDAHULUAN}

Industri grafika, mesin cetak web offset merupakan alat yang sangat penting yang tidak dapat dipisahkan dari perkembangan industri grafika itu sendiri. Hal ini karena mesin cetak adalah merupakan alat utama yang digunakan dalam proses cetak. Oleh karena itu seiring dengan perkembangan industri grafika yang terus berkembang harus diiringi pula dengan perkembangan terhadap teknologi mesin cetak, khususnya mesin cetak ofset yang merupakan teknik cetak paling banyak dipergunakan dalam perusahaan percetakan.

Perkembangan teknologi dan pasar grafika yang terus berubah cepat menjadikan para pelaku industri dituntut harus bisa menyesuaikannya. Faktor waktu memang menjadi daya Tarik bagi industri grafika, perusahaan-perusahaan percetakan yang mencetak buku diknas ini bersaing ketat dalam menjaga kualitas hasil cetakannya. Dalam menjaga kualitas hasil cetakan banyak aspek yang harus diperhatikan oleh percetakan tersebut antara lain waktu produksi/pengerjaan, harga yang diberikan, dan tentunya kualitas produk yang dihasilkan.

Untuk mendapatkan kualitas hasil cetakan buku diknas yang baik sebuah percetakan tidak hanya mengandalkan kecanggihan teknologi mesin cetak yang digunakan saja. Dibutuhkan pula sumber daya manusia yang berkompeten, sebab hal ini sangatlah penting mengingat seorang operator cetak seharusnya tidak hanya bisa mengoprasikan mesin saja, tetapi seorang operator juga harus bisa menjaga kualitas produk yang dihasilkan dengan cara melakukan perawatan yang baik serta tahu bagaimana cara menangani suatu permasalahan yang terjadi pada saat proses cetak berlangsung.

Permasalahan yang sering muncul terhadap kualitas cetakan buku diknas juga dipengaruhi beberapa faktor di antaranya yaitu bahan seperti pengembangan kertas yang menjadi masalah produksi yang agak sulit diatasi karena perubahan ukuran kertas yang diakibatkan oleh pengembangan kertas tidak sama, sehingga sulit menentukan pemecahannya. Arah serat kertas tidak benar juga dapat menjadi penyebab pengembangan kertas. Untuk mengatasi adanya pengembangan kertas, maka diusahakan agar kertas tetap terbungkus rapat sebelum dicetak. Adapun tinta cetak yang kurang baik membuat nilai density tidak stabil. Pemberian chemical seperti campuran air pembasah yang tidak baik yang mengakibatkan pelat cetak cepat rusak. Permasalahan tersebut di atas 
berdampak pada penurunan kualitas cetak.

Kurangnya perhatian dan perawatan terhadap setiap unit di mesin cetak ofset juga terkadang menimbulkan kerusakan pada komponenkomponennya dan menimbulkan permasalahan yang berdampak pada penurunan kualitas cetak isi buku diknas seni budaya.

Proses cetak pun sangat mempengaruhi hasil kualitas cetak isi buku diknas seni budaya. Pada proses cetak pun harus dijaga kestabilan hasil cetakan dengan memperhatikan kestabilan kertas. Kestabilan kertas sangat mempengaruhi hasil lipatan pada unit folding, karena hasil cetakan ofset gulungan berupa lembaran tercetak dan sudah dilipat yang berbentuk katern. Air pembasah dan tinta pun harus dicek agar hasil cetakan baik dengan memperhatikan keseimbangan air dengan tinta. Serta register cetakan yang harus selalu pada posisinya dapat dirumuskan permasalahan yaitu Bagaimana Pengamatan kualitas hasil cetak isi buku diknas Seni Budaya pada mesin web offset DGM430, bagaimana cara melakukan proses perbaikan untuk mengurangi permasalahan penurunan kualitas hasil cetak dan bagaimana solusi untuk mengatasi masalah penurunan kualitas hasil cetak

\section{METODE PENELITIAN}

Metode pengumpulan data dalam penyusunan laporan Tugas Akhir ini penulis menggunakan beberapa metode untuk memperoleh data dan informasi sebagai referensi untuk memecahkan permasalahan yang ada dalam pembuatan karya tulis paper ini, metode-metode yang digunakan yaitu antara lain :

Metode kepustakaan ini dapat dilihat berdasarkan penggunaan literature yang dituangkan dalam pustaka yang di acu (daftar pustaka). Penulis mencari dan mengumpulkan data-data yang diperlukan dari berbagai referensi tambahan seperti buku, makalah, internet, artikel, dan diktat kuliah yang berhubungan dengan judul Tugas Akhir yang penulis buat.tentang Jenis-jenis Mesin Cetak Ofset Gulungan (Web Offset)

Mesin cetak web ofset dibagi menjadi beberapa jenis berdasarkan pengelompokannya yaitu ditinjau berdasarkan bahan baku cetak, ditinjau berdasarkan unit cetak, dan ditinjau berdasarkan konstruksi mesin.

1. Ditinjau Berdasarkan Bahan Baku Produksi

a. Commercial web ofset

Commercial web offset yaitu mesin cetak ofset gulungan (web) yang menangani bahan cetak untuk jenis cetakan komersil seperti buku, majalah yang menggunakan bahan kertas bebas kayu yang biasanya penyerapan 
tintanya lambat. Karena itu pada mesin ini dirangkai unit pengering (dryer) agar tinta dapat cepat mengering setelah dicetak dan tidak terjadi set off pada saat dilakukan penyelesaian akhir (lipat dan potong) dibagikan akhir rangkaian mesin. Seperti gambar 2.12

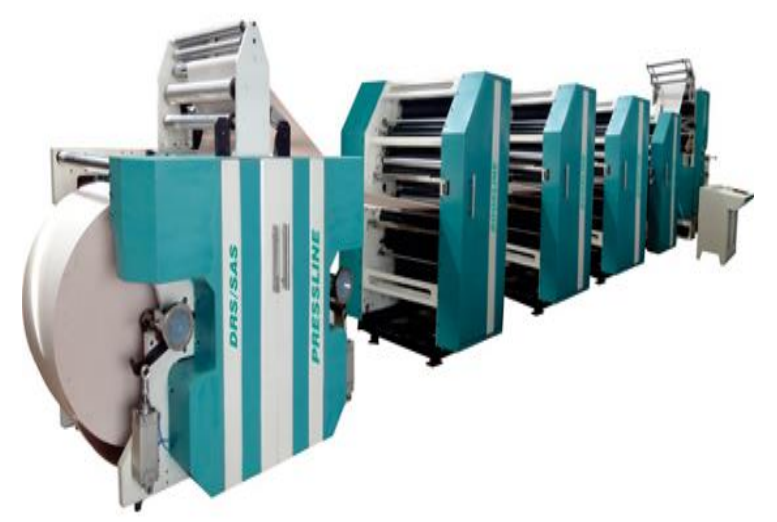

Gambar 1. Commercial web offset

b. Newspaper web offset

Newspaper web offset yaitu mesin cetak ofset gulungan yang khusus mencetak bahan baku kertasnya dengan serat kayu seperti koran yang mudah menyerap tinta dan pengeringannya menggunakan penguapan atau oksidasi. Jadi ini tidak perlu ada tambahan rangkaian pada mesin ini. Seperti gambar 2.

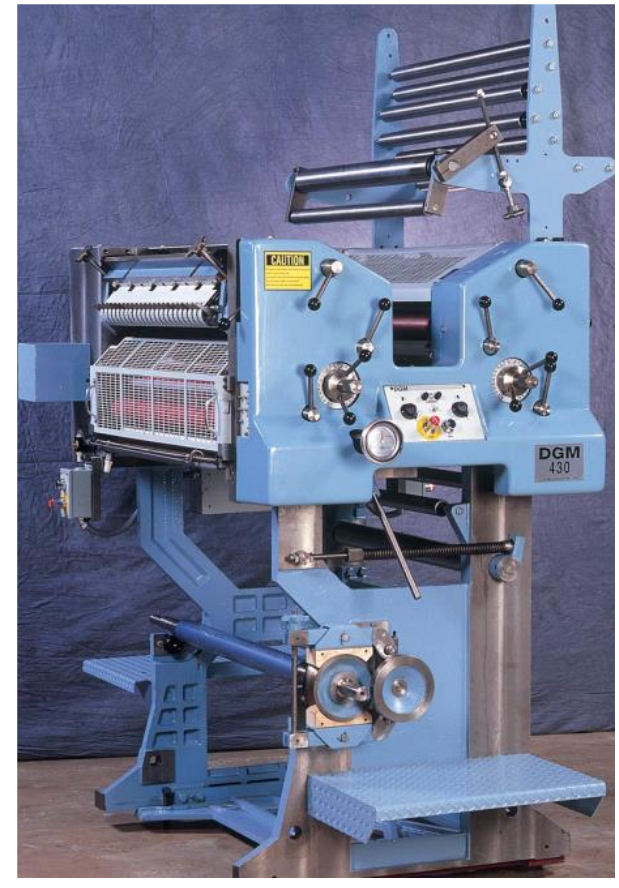

Gambar 2. Newspaper web offset

2. Tipe-Tipe Silinder Cetak Pada Mesin Web Ofset

a. Single width single cyrcum (SWSC)

Tipe SWSC ini maksudnya adalah satu lembar pelat yang terpasang dalam satu silinder, tipe ini memiliki lebar dan keliling silindernya tunggal, (keliling $640 \mathrm{~mm}$ dan lebar $900 \mathrm{~mm}$ ). Seperti gambar 3

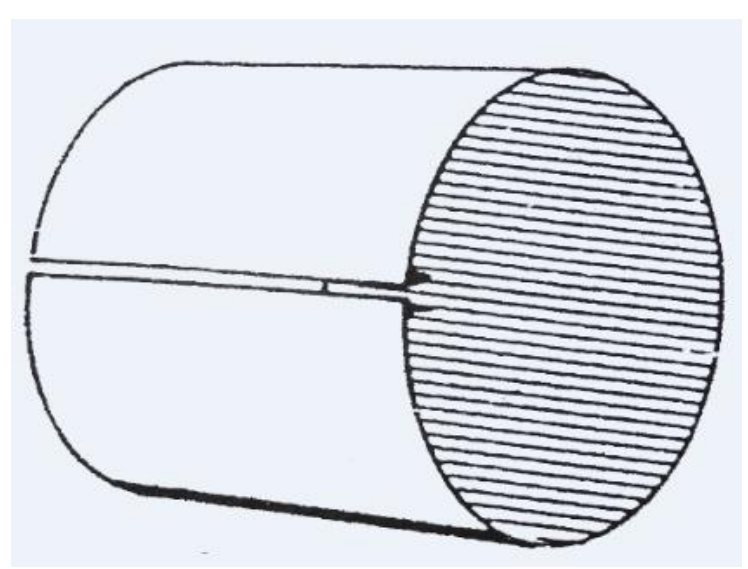

Gambar 3. Konfigurasi SWSC

Double width single cyrcum (DWSC) 
Tipe DWSC ini maksudnya adalah dalam silinder terdapat dua pelat dan oplah yang didapat lebih tinggi dari SWSC, tipe ini memiliki lebar silinder 2x lebar tunggal dan keliling silindernya tunggal, (keliling $640 \mathrm{~mm}$ dan lebar 900 x 2). Seperti gambar 2.15

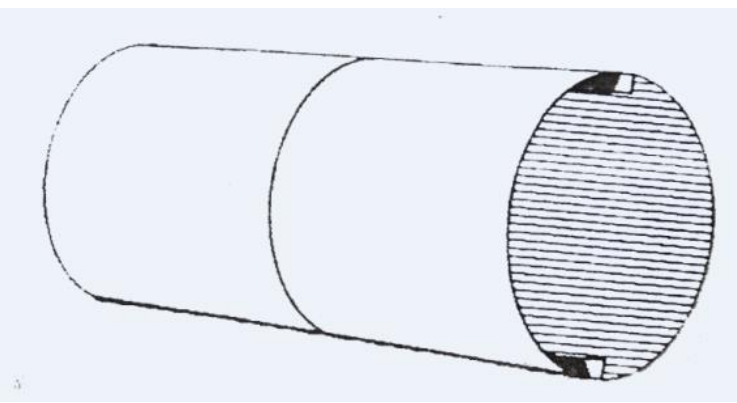

Gambar 4. Konfigurasi DWSC

b. Single width double cyrcum (SWDC)

Tipe SWDC ini maksudya adalah diameter silinder $2 \mathrm{x}$ lebih besar dan dapat menampung 2 lembar pelat sekaligus, tipe ini memiliki lebar silinder tunggal dan keliling silindernya 2x tunggal, (keliling 640 × $2 \mathrm{~mm}$ dan lebar 900). Seperti gambar 5

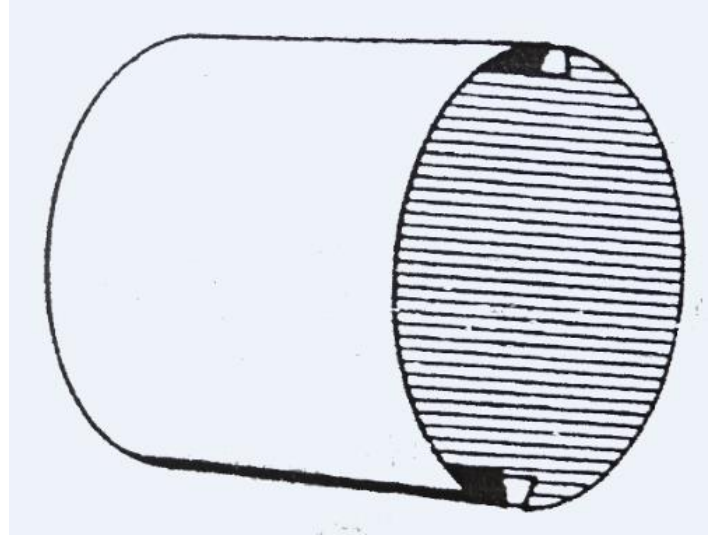

Gambar 5. Konfigurasi SWDC

c. Double widht double cyrcum (DWDC)
Tipe DWDC ini maksudnya adalah diameter silinder $2 \mathrm{x}$ lebih besar dan memiliki lebar silinder $2 x$ jadi dapat memuat 4 lembar 4 pelat dalam 1 lintasan, tipe ini memiliki lebar silinder 2x lebar tunggal dan keliling silindernya 2x tunggal, (keliling 640 x 2 $\mathrm{mm}$ dan lebar 900 x 2). Seperti gambar 2.17

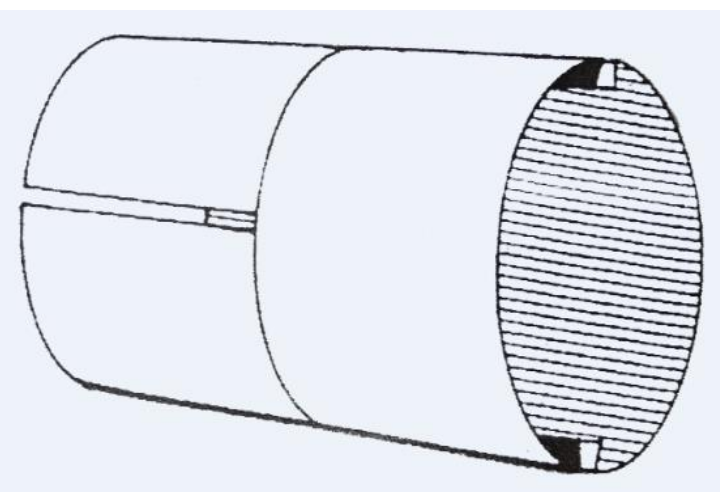

Gambar 6. Konfigurasi DWDC

\section{Kertas}

Kertas merupakan lembaran tipis hasil kempa yang terbuat dari serat selulosia dengan membentuk jalinan yang tidak teratur yang ditambahkan bahan penolong untuk mendapatkan sifat tertentu dari kertas yang akan dibuat.

Kertas dikenal sebagai media utama untuk menulis, mencetak, melukis, dan banyak lagi kegunaan lain yang dapat dilakukan dengan kertas. Pada masa sekarang penggunaan kertas sudah menjadi faktor utama dalam setiap aspek kehidupan manusia dan selain itu kertas juga memegang peranan 
penting dalam industri percetakan.

\section{Kualitas Cetak}

\subsection{Pengertian Kualitas Cetak}

Pengertian dan pendapat tentang kualitas/mutu sangat bervariasi, tergantung dari sudut pandang dan latar belakangnya. Namun demikian, tolok ukur yang dipergunakan dalam menetapkan pengertian kualitas hasil cetak dan sistem adalah sejauh mana tingkat kepuasan pemakai/pengguna terhadap produk atau sistem tersebut. Para produsen atau para pembuat suata karya, pengertian kualitas hasil karyanya itu diartikan sebagai faktor-faktor produksi yang ada dan terdapat didalam komponen barang hasil produksinya.

Secara konvensional, kualitas adalah sesuatu yang menggambarkan karakteristik (seperti ciri dan sifat) langsung dari suatu produk, seperti penampilan/performance, mudah dalam penggunaan/easy to use dan keindahan/estetikalesthetics, dil. Sedangkan dari sisi Strategis , mutu adalah segala sesuatu yang memenuhi keinginan dan kebutuhan pelanggan, tidak hanya kesesuaian atas karakteristik dari produk yang ditawarkan, tetapi juga tingkat pelayanan yang menyertai, seperti cara pemasaran, cara pemasaran, cara pembayaran, ketepatan waktu penyerahan, ketepatan jumlah beserta kemudahankemudahan lain. (Antonius Bowo;Teknik Grafika dan Industri Jilid 3 Kelas

\section{$11 ; 2008: 615)$}

\subsection{Menerapkan Standar Kualitas}

Persaingan dunia usaha kini semakin ketat dan diwarnai dengan perubahan orientasi dari ekonomi produksi ke ekonomi pasar. Persaingan tidak hanya pada produktivitas dan rendahnya harga tetapi lebih pada mutu atau kualitas, kenyamanan, kemudahan, ketepatan, waktu, dan pelayanan. Faktor utama yang menentukan keberhasilan suatu perusahaan adalah mutu barang dan jasa yang dihasilkan. Produk atau jasa yang bermutu adalah yang sesuai dengan keinginan konsumen. Sedangkan mutu itu sendiri yaitu keseluruhan ciri atau karakteristik produk atau jasa dalam tujuannya untuk memenuhi kebutuhan dan harapan pelanggan, Untuk menghasilkan mutu terbaik diperlukan pengawasan yang maksimal selama proses produksi sehingga apabila ada kesalahan atau cacat produk masih bisa diperbaiki sebelum produk akhir. Dengan begitu dapat meminimalisir cacat produk dan juga menekan biaya produksi yang dikeluarkan untuk mengganti produk yang cacat.

Kriteria penilaian terhadap kualitas cetak selama ini sebagian besar percetakan bisa dikatakan masih jarang. Para pencetak hanya berpegang pada proof cetak yang ada dan berupaya menyamakan dengan contoh. Tidak sedikit terjadi kegagalan kualitas produksi cetak seperti warna tidak sama dengan contoh, detail tidak sama dengan 
contoh, register, warna hasil cetakan bervariasi dan cetakan kotor. (Antonius Bowo;Teknik Grafika dan Industri Jilid 3 Kelas 11;2008:615)

Penelitian dan metode observasi lapangan yang dilakukan dengan cara terjun langsung ke lapangan atau perusahaan percetakan menggunakan riset dan penelitian di PT. Gramedia Unit Bandung sesuai dengan judul yang penulis angkat. Dengan cara ini penulis dapat mengumpulkan langsung datadata yang diperlukan.

Fasilitas Perusahaan

Dalam proses pekerjaan, PT Gramedia Unit Bandung memfasilitasi tiaptiap bagian maupun sesuai dengan kebutuhan masing-masing bagian.

Pra Cetak (Pre Press)

Untuk memenuhi kebutuhan dalam proses menerima data, pembuatan pelat cetak, imposisi halaman, dan sebagainya, PT. Gramedia Unit Bandung memfasilitasi bagian Pra Cetak dengan computer dan mesin-mesin sebagai berikut :

\section{A. CTP}

1. Fujifilm Luxel VX 9600 tahun 2007

2. Fujifilm Luxel T-9500 CTP-NS 2007

B. Digital Proofing

1. Printer Epson Stylus Pro 9890

Cetak Ofset

Cetak Web

1. Mesin cetak Goss Community 546
2. Mesin cetak DGM 430

Sarana dan Prasarana di PT. Gramedia Unit Bandung

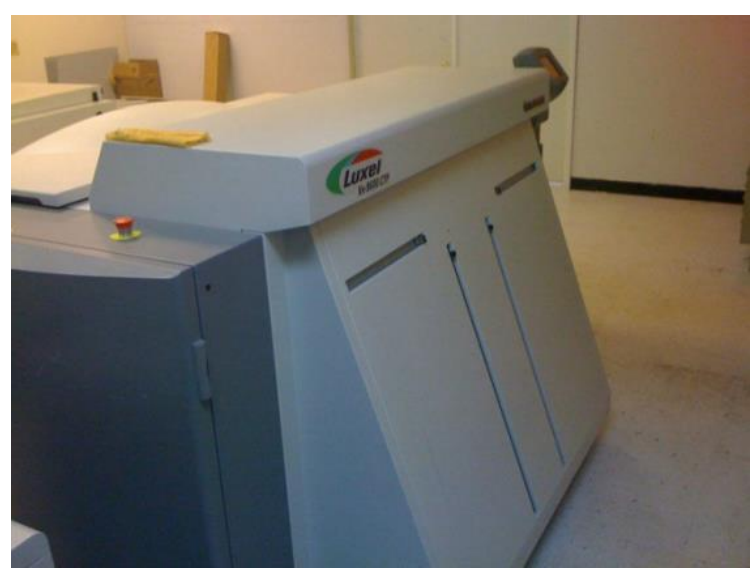

Gambar 7. Mesin Fuji Film Luxel T-9500 CTP-NS a. 23 piring per jam pada 2.400 dpi.

b. Format besar $840 \mathrm{~mm}$ x $1.160 \mathrm{~mm} 8$-up.

c. Penyeimbangan drum otomatis memungkinkan pencatatan berbagai ukuran piring tanpa penyesuaian manual.

d. Empat tingkat resolusi dari 1.200 menjadi 2.540 dpi agar sesuai dengan berbagai pekerjaan.

e. Sistem dua baki yang unik untuk pemuatan dan bongkar muat semi otomatis.

f. Konfigurasi blok pukulan opsional untuk berbagai ukuran piring dan konfigurasi pers. 


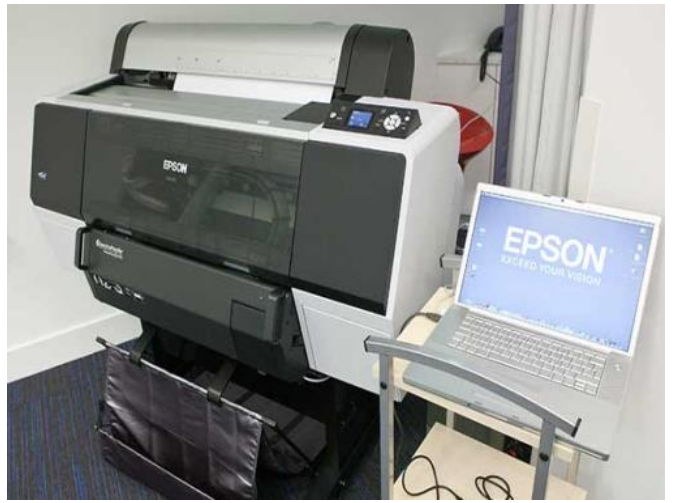

Gambar 8. Mesin Printer Epson Stylus Pro 9890 (Digital Proof)

Spesifikasi Teknis

a. Printheah: MicroPiezo TFP Printhead

b. Ukuran Mesin : 44 Inch

c. Maksimal Resolusi: 2880 x 1440 dpi

d. Maksimal Droplet: $3.5 \mathrm{pl}$

e. Tinta: 8 Warna

f. Kapasitas Tinta: $350 \mathrm{ml} / 750 \mathrm{ml}$

g. Ukuran Kertas Roll: 254 - 610 mm

h. Ukuran Potong Kertas: 210 - $610 \mathrm{~mm}$

i. Ketebalan Kertas: $0.08-1.50$ mm

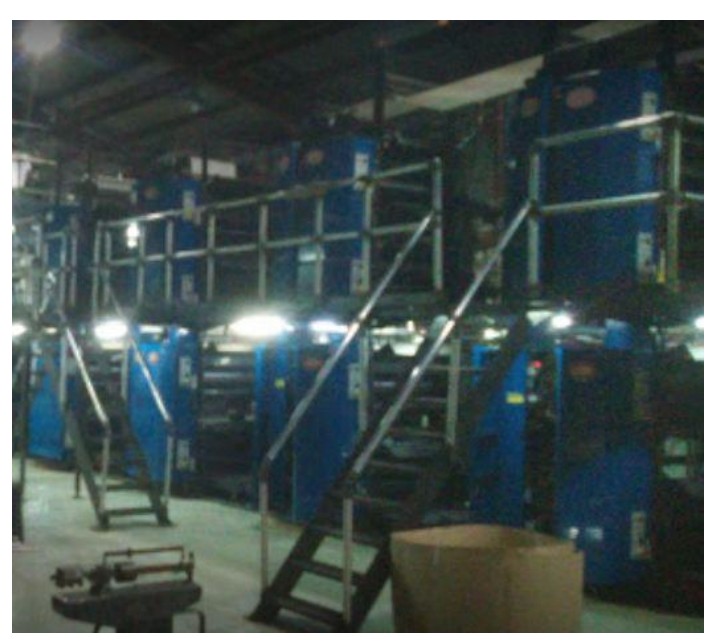

Gambar 9. Mesin Web Offset DGM 430

Spesifikasi Teknis

a. Lebar WEB = 35" Max

b. Max. Kecepatan $=30.000 \mathrm{iph}$

c. Piring Cylinder Sidelay $= \pm 0,125$ " d. Floor Unit $=5.500 \mathrm{lbs}$

e. Stack Satuan $=5250 \mathrm{lbs}$

f. Unit Dasar $=6.000 \mathrm{lbs}$

g. $($ Piring + Packing $)=0,014$ "

h. Cut Off $=578 \mathrm{~mm}$

Spesifikasi Teknis Buku Diknas Seni Budaya

a. Judul Buku : Isi Buku Diknas Seni Budaya SMP VIII

b. Ukuran Buku : $148 \times 210 \mathrm{~mm}$

c. Cetak Isi : 4/4 warna

d. Cetak Cover : 4/0 warna (Vernish Glossy)

e. Jenis Kertas Isi Buku : Aspex 80 gram

f. Jenis Kertas Cover : Art Paper 210 gram

g. Isi Buku / vel : 16 halaman/vel

h. Jenis Lipatan : Lipatan Quarter Fold / Magazine

i. Oplah Cetak : 15.000 ekstemplar

j. Cut off Mesin : 63

k. Jenis Jilid Buku : Perfect Binding

Penulis melakukan wawancara dan diskusi langsung dengan pihak-pihak yang berhubungan dengan objek penelitian guna memperoleh penjelasan mengenai data yang akurat dan jelas serta untuk mendapatkan solusi terbaik dari setiap permasalahan yang timbul pada proses perawatan berlangsung.

\section{HASIL DAN PEMBAHASAN}




\section{Pengamatan kualitas hasil cetak isi buku diknas Seni Budaya pada mesin web offset DGM430}

Berdasarkan pengumpulan data yang telah dilakukan di PT. Gramedia Unit Bandung, pada bab ini akan dibahas masalah yang sering timbul pada hasil cetak isi buku diknas seni budaya yang membuat kualitas hasil cetak isi buku diknas seni budaya menurun di Mesin Cetak Web Offset DGM 430. Hal ini dapat berdampak terhadap kualitas cetak isi buku diknas seni budaya yang akan diterbitkan pada keesokan harinya. Adapun permasalahan yang terjadi pada hasil cetak isi buku diknas seni budaya seperti berikut :

\subsection{Miss Register}

Miss Register adalah ketidaktepatan cetak antara warna yang satu dengan yang lain. Hal ini dapat mempengaruhi hasil cetakan yang terjadi dan membuat kualitas cetakan menurun. Berikut adalah faktor yang mempengaruhi miss register pada saat proses cetak isi buku diknas seni budaya pada mesin web ofset DGM 430 di PT. Gramedia Unit Bandung, yaitu:

1. Kertas

Kertas yang digunakan keriput, dikarenakan oleh saat penyimpanan kertas dengan perpindahan kertas saat ingin dipakai mengalami perubahan suhu kelebaban pada ruangan.

2. Mesin

a. Blanket kendor tidak adanya pengecekan terlebih dahulu sebelum berjalannya proses cetak

b. Lintasan pertama kertas lebih tinggi dari lintasan berikutnya.

c. Ketegangan pada kertas kendor

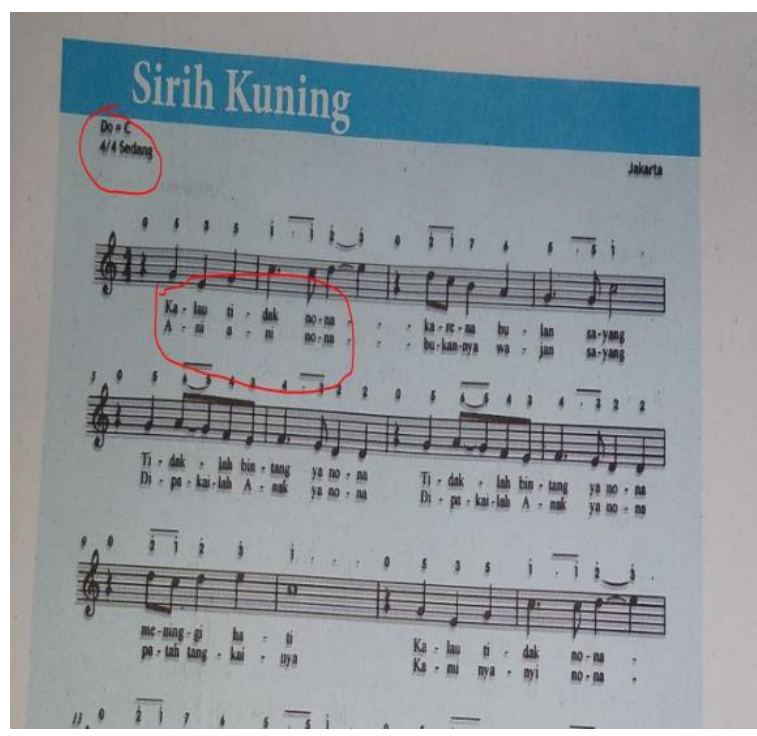

Gambar 10. Cetakan Miss Register

\subsection{Set Off}

Tinta lambat kering yang mengakibatkan penularan cetakan pada cetakan selanjutnya. Hal ini akan berdampak terhadap hasil cetakan selanjutnya karena terdapat jejak cetakan pertama. Berikut adalah faktor yang mempengaruhi set off pada saat proses cetak isi buku diknas seni budaya pada mesin web ofset DGM 430 di PT. Gramedia Unit Bandung, yaitu:

1. Mesin 
- Belt penghantar kotor.

- Pemakaian tinta terlalu tebal saat proses produksi.

- Pemberian tinta tidak stabil.

- Rol penghantar kertas berkarat atau kotor

- Tekanan pada unit pencetakan terlalu berat.

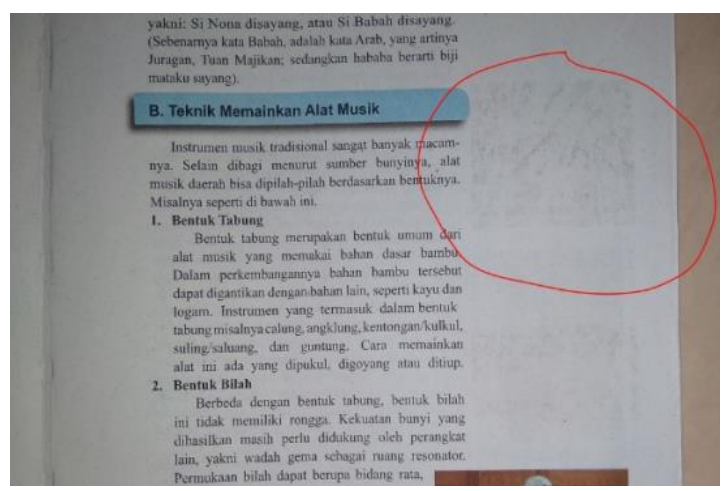

Gambar 11. Cetakan Set Off

\subsection{Scumming}

Scumming adalah kondisi yang terjadi pada cetak ofset, di mana pelat pada daerah non image menjadi peka dan mulai menerima tinta. Hal ini disebabkan area pelat cetaknya mulai menyerap tinta dan menolak air pembasah. Berikut adalah faktor yang mempengaruhi scumming pada saat proses cetak isi buku diknas seni budaya pada mesin web ofset DGM 430 di PT. Gramedia Unit Bandung, yaitu:

\section{Mesin}

a. Sarung rol air rusak karena tidak dapat mendistribusikan air pembasah dengan maksimal.

b. Unit pembasahan tidak sesuai pengaturannya yang menyebabkan supply air pembasah tidak sesuai dengan kebutuhan.

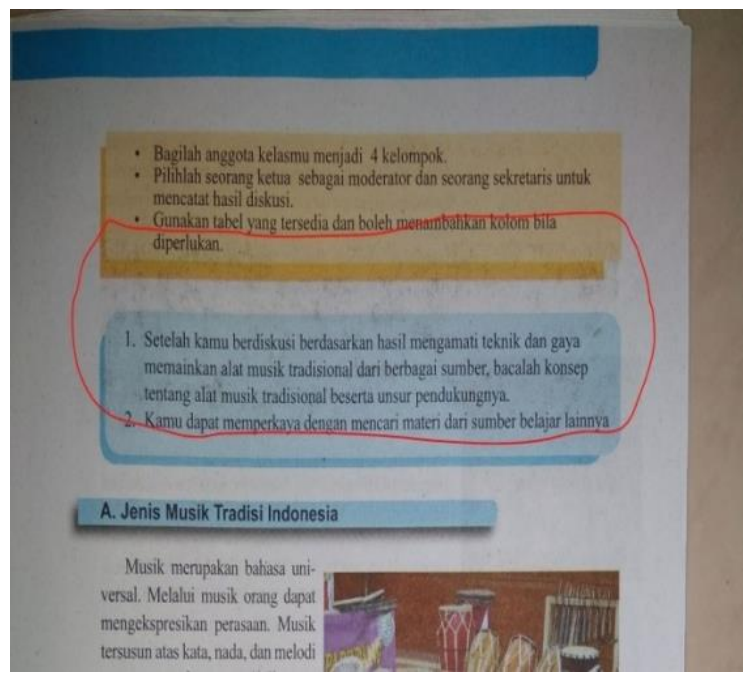

Gambar 12. Cetakan Scumming

\subsection{Blocking}

Blocking adalah merupakan kondisi di mana distribusi image yang terjadi dengan tidak sempurna ke bagian permukaan kertas. Hal ini akan berdampak pada hasil cetakan yang tidak terlihat jelas kemungkinan tingkat daya terbaca bisa menurun. Berikut adalah faktor yang mempengaruhi blocking pada saat proses cetak isi buku diknas seni budaya pada mesin web ofset DGM 430 di PT. Gramedia Unit Bandung, yaitu:

\section{Mesin}

a. Rol pembasahan timpang atau tidak seimbang dalam pergerakan untuk mendistribusikan air pembasah.

b. Air pembasah di bak unit/bak sentral habis 


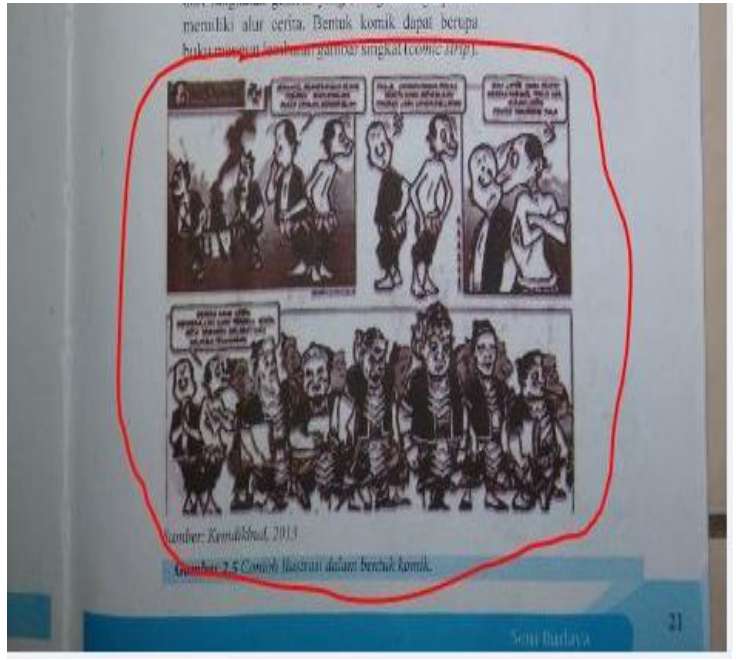

Gambar 13. Cetakan Blocking

\subsection{Kertas Keriput/Flui}

Kertas Keriput/Flui disebabkan karena tegangan kertas yang terlalu berat dan rol-rol hantar yang kurang simetris serta kertas yang lembab, sehingga membuat lembaran kertas melekuk pada bagian tengah. Hal ini dapat membuat hasil cetakan tidak dapat tercetak karena pada saat proses cetak berlangsung perpindahan image terhalang oleh kertas yang terlipat pada bagian tengah kertas dan hal ini juga dapat menyebabkan kertas dapat putus pada saat proses cetak berlangsung. Apabila kertas putus akan menambah panjang waktu proses pencetakan karena operator harus melakukan webbing ulang. Berikut adalah faktor yang mempengaruhi kertas keriput/flui pada saat proses cetak isi buku diknas seni budaya pada mesin web ofset DGM 430 di PT. Gramedia Unit Bandung, yaitu:
1. Kertas

a. Kualitas kertas yang digunakan kurang baik.

b. Ketegangan kertas kurang baik saat proses produksi.

2. Mesin

a. Tekanan blanket kendor atau kurang tekanan

b. Rol penghantar kertas tidak sesuai dengan timming kecepatan mesin, mengakibatkan kertas terputus

c. Tekanan sepatu web break terhadap kertas terlalu kuat.

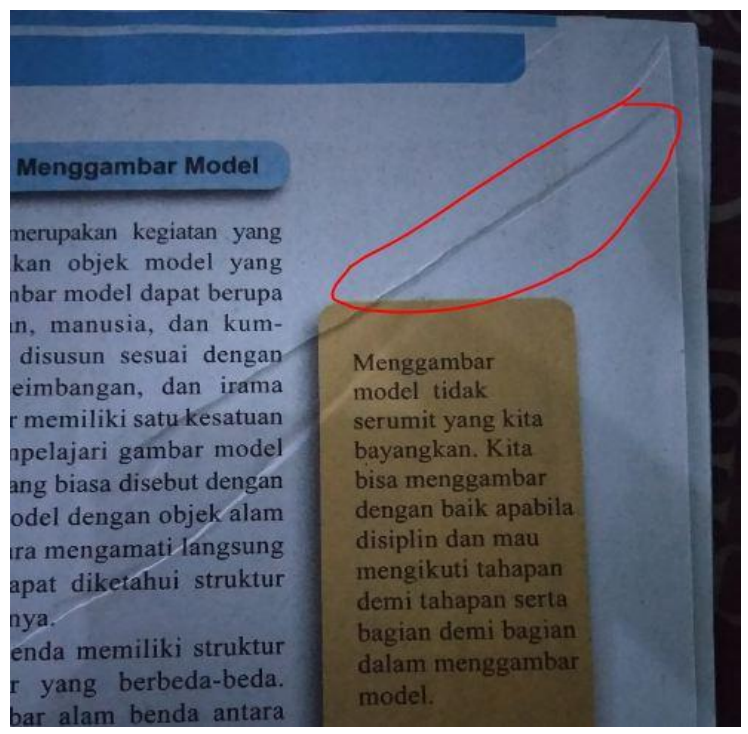

Gambar 14. Cetakan Kertas Keriput / Flui

2 Proses perbaikan untuk mengurangi permasalahan penurunan kualitas hasil cetak

\subsection{Persiapan Mesin}

Pastikan sebelum memasuki ruang produksi / akan memulai pekerjaan kita diwajibkan untuk memakai APD (Alat Pelindung Kerja) agar melindungi kita saat 
bekerja. APD diantaranya:
a. Pakaian Kerja
b. Sepatu Kerja
c. Masker
d. Alat Pelindung Telinga (Ear Plugh / Peltor)

1. Umum

a. Hubungkan (kopel) unit cetak yang akan digunakan.

b. Pasang roll kertas di reelstand.

c. Tarik web pada lintasan yang dikehendaki, atur posisi kompensator, pasang web berak detector (jika ada).

d. Putar control register ke nol.

e. Folder diatur sesuai dengan keperluan

f. Pasang blanket dan pelat.

g. Lepaskan kopeling folder.

h. OFF-kan Impression.

i. Tekan tombol reset pencacah.

j. Periksa tinggi muka oli disemua unit dan folder.

k. Lumasi bagian-bagian pada unit dan folder sesuai dengan petunjuk.

1. Buka tutup udara tekan untuk mesin (jika menggunakan sistem pneumatic).

m. Jika menggunakan dryer, periksa dan bersihkan sampah kertas yang dapat menyumbat saluran udara di dalam dryer.

2. Sistem Penintaan

a. Isi semua bak tinta yang akan digunakan. Kalau masih ada tinta sisa dari pekerjaan sebelumnya, aduk sampai rata. b. Atur bukaan tuas baut kunci tinta sesuai dengan perkiraan kebutuhan penintaan gambar pada pelat di masing-masing unit.

c. Tutup aliran tinta pada bagian yang tidak mencetak.

d. Oleskan pelumas roll ke seluruh permukaan roll yang tidak bertinta.

3. Sistem Pembasah

a. Bersihkan bak air jika perlu.

b. Periksa jumlah air di dalam reservoir sistem sirkulasi

c. Periksa aliran air antara reservoir dan bak air

d. Periksa $\mathrm{pH}$ dan konduktivitas air pada reservoir sistem sirkulasi.

e. Isi bak air di unit.

f. Pasang penahan air pada roll bak air sesuai keperluan.

2.2 Standar Operasional Prosedur (SOP) Mesin DGM 430 Web Offset pada Proses Cetak Isi Buku Diknas Seni Budaya

Dalam pengoprasian mesin DGM 430 Web Offset, penulis dapat memperhatikan para operator dalam pengoprasian mesin ini, di mana dalam melakukan pencetakan ada yang namanya Start-up yaitu proses awal dalam mengoperasikan mesin cetak web. Pada proses ini operator dituntut untuk menghasilkan kualitas cetakan yang baik dengan mengacu pada standar DCP (Digital Color Proofing). Ketepatan register, warna, cut off, harus disesuaikan pada SOP (Standart Opertional Prosedure) yang sudah ditetapkan 
perusahaan.

Adapun SOP (Standart Operational Prosedure) cetak isi buku Diknas Seni Budaya, antara lain :

1. Pemeriksaan judul dan tanggal cetakan

Hal ini bertujuan agar tanggal judul cetakan sesuai dengan tanggal yang akan dilakukan proses cetak. Langkah-langkah yang harus dilakukan untuk pengecekan yaitu dengan cara membuka setiap lembar dan perhatikan tanggalan pada pojok kanan atas pada sudah sesuai dengan SPK (Surat Perintah Kerja) atau tidak. Kalau salah tanggal dan judul cetak harus secepatnya hubungi kepala leader operator ataupun Kepala Bagian yang bertanggung jawab untuk melakukan revisi.

2. Pemeriksaan halaman sesuai dengan urutan

Pemeriksaan halaman harus dilakukan agar tidak terjadi halaman terbalik. Harus sesuai dengan urutan dari awal halaman hingga akhir halaman. Langkah-langkah yang dilakukan yaitu pengecekan lembar demi lembar apa nomor halamannya sudah sesuai atau tidak. Jikalau salah imposisi halaman atau penempatan halaman secepatnya hubungi bagian Pre Press atau kepada Kepala Bagian yang bertanggung jawab untuk melakukan revisi.

3. Register pada cetakan warna

Pemeriksaan register harus selalu dicek setiap lembarnya agar tidak terjadi miss register. Karena proses pencetakan isi buku Diknas Seni Budaya yang pencetakanya di mesin ofset gulungan dengan kecepatan tinggi, maka proses pemeriksaan harus selalu di monitor agar tidak terjadi banyak cetakan yang dibuang karena miss register (waste). Langkah-langkah untuk mengatur register yaitu dengan mengaturnya di meja pengaturan register.

\section{Cut Off cetakan}

Periksa ukuran cut off cetakan apa sudah sesuai dengan standar yang berlaku di perusahaan atau belum. Jika tidak sesuai harus secepatnya disesuaikan dengan jarak atas dan bawah $1 \mathrm{~cm}$. Langkah-langkah untuk mengatur cut off yaitu dengan mengubah tarikan roll kompensator.

5. Sidelay kertas

Seting sidelay kertas agar cetakan tertata rapih. Langkah-langkah untuk mengatur sidelay yaitu dengan cara mengatur tarik dorong kertas pada unit reelstand.

6. Kerataan tinta

Kerataan tinta harus dilakukan agar hasil cetakan sesuai dengan DCP (Digital Color Proofing). Langkah-langkah untuk mengatur kerataan tinta yaitu pada meja consul mesin warna.

7. Ketepatan tanda lipat

Ketepatan tanda lipat harus dilakukan agar posisi cetakan ada pada posisi tengah 
kertas dan tidak terjadi hambatan saat masuk dalam unit folder untuk pelipatan. Langkahlangkah untuk mengaturnya yaitu dengan mengubah tekanan nipping roll dan roll bending pada unit folder.

2.3 Penyebab Terjadinya Penurunan Kualitas Hasil Cetak Isi Buku Diknas Seni Budaya pada mesin Web Offset DGM 430

Ada beberapa masalah yang paling sering terjadi pada saat proses cetak isi buku diknas seni budaya yang menyebabkan penurunan kualitas cetak isi buku diknas seni budaya di PT. Gramedia Unit Bandung diantaranya:

a. Kurangnya perhatian pada perawatan mesin tersebut.

b. Kurangnya pemerhatian cymical kertas pada perbedaan suhu ruangan.

c. Kurangnya pemerhatian pengukuran tinta cetak yang dipakai tidak sesuai dengan media kertas yang dipakai.

d. Kurangnya pengecekan dalam pengukuran dan pemakaian air pembasah saat proses tersebut.

e. Kurangnya perhitungan pengeluaran pada unit folder saat pelipatan cetakan.

f. Miss Comunication pada Operator yang mengoperasikan mesin yang sedang beroperasi.

g. Kurangnya tanggapan cepat operator terhadap masalah yang telah terjadi pada cetakan tersebut. h. Operator tidak mengoperasikan mesin sesuai standar operasional prosedur.

\section{Solusi untuk mengatasi masalah} penurunan kualitas hasil cetak

Berikut ini dijelaskan bagaimana cara mengatasi masalah-masalah yang sering timbul pada hasil cetakan isi buku Diknas Seni Budaya yang membuat kualitas hasil cetak isi buku Diknas Seni Budaya menurun di Mesin Cetak Web Offset DGM430 beserta permasalahan dan solusinya :

\subsection{Miss Register}

Tabel 1. Miss Register

\begin{tabular}{|c|c|c|}
\hline $\mathrm{NO}$ & Penyebab & Cara Mengatasi \\
\hline 1 & $\begin{array}{l}\text { Karenakan } \\
\text { kertas yang } \\
\text { mengembang. }\end{array}$ & $\begin{array}{l}\text { Usahakan agar } \\
\text { kertas tertutup } \\
\text { rapat sebelum } \\
\text { dicetak }\end{array}$ \\
\hline 2 & $\begin{array}{l}\text { Kekuatan } \\
\text { Tension } \\
\text { (tegangan) } \\
\text { pada unit } \\
\text { reelstand } \\
\text { tidak stabil. }\end{array}$ & $\begin{array}{l}\text { Mengatur } \\
\text { tegangan dancing } \\
\text { roll pada saat } \\
\text { mesin berjalan, } \\
\text { tegangan yang } \\
\text { diberikan harus } \\
\text { disesuaikan } \\
\text { dengan jenis } \\
\text { kertas gulungan } \\
\text { yang digunakan, } \\
\text { pada jenis kertas } \\
\text { isi buku tegangan } \\
\text { yang diberikan } \\
\text { adalah } 1 \text { bar pada }\end{array}$ \\
\hline
\end{tabular}


Vol. 6, No. 2, Oktober 2019, hal. 104-121

\begin{tabular}{|c|c|c|}
\hline & & $\begin{array}{l}\text { saat mesin } \\
\text { berjalan pelan } \\
\text { dan } 2,5 \text { bar pada } \\
\text { saat mesin } \\
\text { dengan kecepatan } \\
\text { yang konstan atau } \\
\text { stabil. } \\
\text { Pengecekan } \\
\text { terhadap kondisi } \\
\text { mekanisme rantai } \\
\text { dan kondisi rem } \\
\text { penahan yang } \\
\text { dapat } \\
\text { mempengaruhi } \\
\text { ketegangan } \\
\text { kertas. }\end{array}$ \\
\hline 3 & $\begin{array}{l}\text { Pengaturan } \\
\text { pelat pada } \\
\text { mesin tidak } \\
\text { baik. }\end{array}$ & $\begin{array}{l}\text { Lakukan } \\
\text { pengaturan ulang } \\
\text { terhadap mesin. }\end{array}$ \\
\hline
\end{tabular}

\subsection{Set Off}

Tabel 2. Set Off

\begin{tabular}{|l|l|l|}
\hline NO & Penyebab & Cara Mengatasi \\
\hline 1 & Tinta & Tambahkan \\
& mengering & temperature dryer \\
& terlalu lama. & atau pengeringan \\
& & $1-2 \%$. \\
& & Kurangi kecepatan \\
& & pada mesin. \\
& & Kurangi supply \\
& & tinta dari bak tinta \\
\end{tabular}

\begin{tabular}{|l|l|}
\hline & $\begin{array}{l}\text { pada meja konsul } \\
\text { untuk mengurangi } \\
\text { ketebalan tinta. }\end{array}$ \\
\hline
\end{tabular}

\subsection{Scumming}

Tabel 3. Scumming

\begin{tabular}{|c|c|c|}
\hline NO & Penyebab & $\begin{array}{l}\text { Cara } \\
\text { Mengatasi }\end{array}$ \\
\hline 1 & $\begin{array}{l}\text { Pemberian tinta } \\
\text { terlalu berlebihan } \\
\text { saat mencetak } \\
\text { pada nada } \\
\text { halftone atau } \\
\text { mencetak dengan } \\
\text { tinta terlalu encer, } \\
\text { hal ini } \\
\text { menyebabkan } \\
\text { tinta melebar ke } \\
\text { area non image } \\
\text { dan perlahan- } \\
\text { lahan } \\
\text { menyebabkan } \\
\text { area tersebut } \\
\text { menjadi sensitif. }\end{array}$ & $\begin{array}{l}\text { Tinta } \\
\text { sebaiknya di } \\
\text { proses ulang } \\
\text { dalam } \\
\text { penggunaan } \\
\text { yang sesuai. } \\
\text { Ganti } \\
\text { pemakaian } \\
\text { jenis tinta. }\end{array}$ \\
\hline 2 & $\begin{array}{l}\text { Fountain Solution } \\
\text { kurang baik. }\end{array}$ & $\begin{array}{l}\text { Periksa } \mathrm{pH} \\
\text { air (agar } \\
\text { nilainya ideal } \\
5-6) .\end{array}$ \\
\hline 3 & $\begin{array}{l}\text { Tekanan rol air } \\
\text { tidak baik. }\end{array}$ & $\begin{array}{l}\text { Atur tekanan } \\
\text { rol air agar } \\
\text { sesuai dengan } \\
\text { kebutuhan }\end{array}$ \\
\hline
\end{tabular}




\begin{tabular}{|l|l|l|}
\hline & & $\begin{array}{l}\text { saat proses } \\
\text { mencetak. }\end{array}$ \\
\hline 4 & $\begin{array}{l}\text { Kurangnya } \\
\text { supply air ke } \\
\text { bagian pelat. }\end{array}$ & $\begin{array}{l}\text { Tambahkan } \\
\text { nilai potensi } \\
\text { air. }\end{array}$ \\
\hline
\end{tabular}

\subsection{Blocking}

Tabel 4. Blocking

\begin{tabular}{|c|c|c|}
\hline $\mathrm{NO}$ & Penyebab & Cara Mengatasi \\
\hline 1 & $\begin{array}{l}\text { Rol } \\
\text { Pembasahan } \\
\text { timpang atau } \\
\text { tidak } \\
\text { seimbang saat } \\
\text { proses cetak } \\
\text { berlangsung. }\end{array}$ & $\begin{array}{l}\text { Cek rol } \\
\text { pembasahan saat } \\
\text { sebelum } \\
\text { menjalankan } \\
\text { mesin untuk } \\
\text { produksi. Jika rol } \\
\text { pembasahan } \\
\text { tersebut } \\
\text { ditemukan tidak } \\
\text { layak ganti } \\
\text { dengan rol } \\
\text { pembasahan } \\
\text { yang baru. } \\
\text { Atur ulang } \\
\text { kembali seting } \\
\text { rol pembasah } \\
\text { tersebut. }\end{array}$ \\
\hline 2 & $\begin{array}{l}\text { Air pembasah } \\
\text { di bak unit / } \\
\text { bak sentral } \\
\text { habis. }\end{array}$ & $\begin{array}{l}\text { Selalu rutin } \\
\text { untuk } \\
\text { pengecekan air } \\
\text { pembasah pada } \\
\text { bak unit sentral } \\
\text { sebelum proses }\end{array}$ \\
\hline
\end{tabular}

\begin{tabular}{|l|l|}
\hline & $\begin{array}{l}\text { produksi } \\
\text { berjalan. } \\
\text { Jika air bak } \\
\text { sentral habis isi } \\
\text { kembali air } \\
\text { pembasah sesuai } \\
\text { kebutuhan yang } \\
\text { ingin dipakai. } \\
\text { Pengukuran air } \\
\text { pembasah sesuai } \\
\text { dengan } \\
\text { penggunaan } \\
\text { yang ingin } \\
\text { dipakai. }\end{array}$ \\
\hline
\end{tabular}

\subsection{Kertas Keriput / Flui}

Tabel 5. Kertas Keriput / Flui

\begin{tabular}{|c|c|c|}
\hline $\mathrm{NO}$ & Penyebab & Cara Mengatasi \\
\hline 1 & $\begin{array}{l}\text { Rol kertas } \\
\text { kurang baik. }\end{array}$ & $\begin{array}{l}\text { Ganti rol kertas } \\
\text { dengan } \\
\text { baru dan } \\
\text { kembali } \\
\text { rol }\end{array}$ \\
\hline
\end{tabular}




\begin{tabular}{|l|l|l|}
\hline & & $\begin{array}{l}\text { kertas cacat atau } \\
\text { rusak harus } \\
\text { segera diganti. }\end{array}$ \\
\hline 2 & $\begin{array}{l}\text { Rol fastoon } \\
\text { tidak simetris. }\end{array}$ & $\begin{array}{l}\text { Atur kemiringan } \\
\text { rol-rol faston } \\
\text { agar tidak terjadi } \\
\text { kemiringan. }\end{array}$ \\
\hline 3 & $\begin{array}{l}\text { Ketegangan } \\
\text { kertas terlalu } \\
\text { berat. }\end{array}$ & $\begin{array}{l}\text { Atur tekanan } \\
\text { (tension) sesuai } \\
\text { dengan jenis } \\
\text { kertas yang akan } \\
\text { dipakai. }\end{array}$ \\
\hline
\end{tabular}

\section{KESIMPULAN}

Setelah penulis melakukan pengamatan di lapangan bahwa penyebab terjadinya penurunan kualitas cetak itu dikarenakan seperti yang sudah dibahas pada bab IV. Maka pentingnya kualitas hasil cetakan itu sangat berpengaruh terhadap harga jual dan juga kesetiaan pelanggan yang membaca buku Diknas Seni Budaya. Dari penjelasan sebelumnya maka didapat beberapa kesimpulan yang ingin disampaikan penulis, yaitu:

1. Penurunan kualitas hasil cetakan dapat dipengaruhi beberapa faktor di antaranya bahan baku yang tidak baik, perawatan mesin, tinta cetak, kondisi air pembasah yang tidak stabil dan proses prepress yang kurang baik.
2. Dari proses persiapan belum adanya kesesuaian dengan SOP (Standart Operational Prosedure) yang ditetapkan oleh pihak perusahaan, maka terjadinya penurunan kualitas pada hasil cetakan. Yang disebabkan oleh kurangnya perhatian proses cetak, pelatihan bagi operator, dan penempatan Sumber Daya Manusia (SDM) yang sesuai dengan bidangnya.

3. Kurangnya standar kualitas yang diterapkan pada perusahaan akan membuat kualitas hasil cetakan tidak stabil/konsisten dan hanya mengacu pada proofing, jarangnya melakukan perawatan dan pengecekan pada kondisi mesin, pengendalian Quality Control yang diterapkan oleh perusahaan tidak sesuai dengan standar, dan ketidak sesuaian penanggapan solusi pada permasalahan yang timbul pada hasil cetakan yang seharusnya diatasi sesuai dengan prosedur.

\section{Saran}

Berikut ini dipaparkan saran atau masukan untuk perusahaan agar dikemudian hari perusahaan lebih memperhatikan proses persiapan awal sebelum produksi cetak dilakukan

1. Bahan cetak yang digunakan sebaiknya mempunyai kualitas yang berstandar. 
Agar permasalahan yang sering timbul pada hasil cetakan surat kabar dapat diminimalisirkan.

2. Dalam melakukan proses pencetakan harus memperhatikan standar kualitas yang berlaku di perusahaan.

3. Lebih sering memperhatikan perawatan mesin yang digunakan produksi cetak, karena kondisi mesin juga mempengaruhi kualitas hasil cetakan. Hal ini dapat mengurangi permasalahanpermasalahan yang sering terjadi pada saat proses produksi berlangsung.

4. Memberikan pelatihan atau seminar kepada semua operator mesin cetak agar dapat memudahkan operator dalam menangani masalah atau kendala yang terjadi pada mesin ctak pada saat proses produksi cetak.

5. Perusahaan harus meningkatkan penerapan program Kesehatan dan
Keselamatan Kerja pada lingkungan industri.

\section{REFERENSI}

Buku Pengetahuan Tinta Cetak Tahun 2008

Faktor-faktor Yang Mempengaruhi keefektifan Fountain Solusion 2003

Manual Book DGM 430

Modern Lithography, Ian Faux, 1973

Teknik Grafika dan Industri Jilid 1 Kelas 10 Tahun 2008

Teknik Grafika dan Industri Jilid 2 Kelas 11 Tahun 2008

Teknik Grafika dan Industri Jilid 3 Kelas 12 Tahun 2008

Teori Dasar Cetak Ofset Politeknik Negeri Media Kreatif

Pedoman Pengujian Kertas dan Tinta Tahun 1999 